\title{
EKSISTENSI PARTAI PERSATUAN DAYAK PADA PEMILU 1955
}

\section{THE EXISTENCE OF DAYAK UNITED PARTIES IN THE 1955 GENERAL ELECTION}

\author{
M. Rikaz Prabowo \\ Guru Sejarah SMA Negeri 10 Pontianak, Kalimantan Barat \\ rikaz.prabowo@gmail.com
}

\begin{abstract}
Abstrak: Penelitian ini bertujuan untuk mendeskripsikan: (1) Kebangkitan politik Dayak sebelum Pemilu 1955 (2) Perjuangan PPD Menghadapi Pemilu 1955, (3) Dampak Kemenangan PPD Pasca Pemilu 1955. Penelitian ini menggunakan metode sejarah kritis. Berdasarkan hasil penelitian dapat disimpulkan: pertama, gerakan politik masyarakat Dayak khususnya di Kalimantan Barat mulai bangkit setelah proklamasi kemerdekaan Indonesia dengan berdirinya Dayak In Action (DIA) pada tanggal 3 November 1945. Ia kemudian berubah menjadi PPD pada tanggal 30 November 1946. Kedua, PPD juga melakukan konsolidasi dan kaderisasi, memaksimalkan potensi akar rumput masyarakat Dayak, serta melakukan kampanye di daerah. Ketiga, PPD berhasil memenangkan Pemilu 1955 dan menduduki posisi-posisi strategis. pemerintahan di eksekutif dan legislatif. PPD juga mengirimkan wakilnya untuk DPR-RI dan daerah pemilihannya. Selain itu, PPD berhasil mengantarkan J. C Oevaang Oeray terpilih menjadi Gubernur Kalbar.
\end{abstract}

Kata Kunci : PPD, J.C Oevaang Oeray, Pemilu 1955, Kalimantan Barat

Abstrac: This Research aims to describe: (1) Dayak political awakening before election 1955 (2) The struggle PPD in the face of election 1955, (3) Impact PPD post-election victory 1955. This study uses a critical history method. Based on the results of the research can be concluded: first, the political movement of Dayak society, especially in West Kalimantan, began to rise after the proclamation independence of Indonesia with the founding of Dayak In Action (DIA) on 3 November 1945. He was later changed to PPD on 30 November 1946. Secondly, The PPD also conducts consolidation and cadre, maximizing the grassroots potential of the Dayak community, as well as conducting the campaigns in areas.Third, PPD successfully won the 1955 election and occupied strategic positions of government in both the executive and legislative. PPD also sent his deputy for DPR-RI and constituency. In addition, PPD managed to deliver J. C Oevaang Oeray was elected as the Governor of the regional head of West Kalimantan.

Keywords: PPD, J.C Oevaang Oeray, Pemilu 1955, Kalimantan Barat 


\section{PENDAHULUAN}

Berbicara tentang berdirinya Partai Persatuan Dayak (PPD), maka tidak bisa dilepaskan dari kondisi masyarakat Dayak itu sendiri sebelumnya. Sebab, bagaimanapun juga suatu partai politik pastilah memiliki suatu tujuan yang hendak dicapai dari sebuah latar belakang. Suku Dayak (dahulu ditulis Day') ialah suatu suku asli yang menempati wilayah Pulau Kalimantan dan dahulunya hidup berkelompok-kelompok dengan mata pencaharian utama adalah berburu, berladang, dan memanfaatkan hasil hutan sebaik-baiknya. Hutan dan Suku Dayak adalah hal yang tidak bisa dipisahkan, sebab bagi mereka hutan adalah tempat suci dan hutanlah yang memberi mereka kehidupan.

Suku Dayak sendiri sebenarnya terdiri dari banyak sub-suku yang berbeda pula bahasanya. Harus diakui masyarakat Dayak saat itu cukup tertinggal dalam berbagai aspek. Ketertinggalan ini ada yang memang terbentuk karena sifat-sifat alamiah masyarakat Dayak yang tetap ingin tinggal di pedalaman menjalankan adat dan tradisi. Akan tetapi ada juga yang memang sengaja diciptakan baik oleh Pemerintah Kolonial Hindia Belanda maupun oleh kesultanan-kesultanan feudal-lokal.

Masyarakat Dayak kala itu melihat masyarakat Melayu sebagai simbol kemajuan. Akan tetapi ketika masyarakat Dayak berupaya untuk mencapai kemajuan tersebut, sistem pendidikan yang ada tidak memberikan kesempatan bagi anak-anak Dayak. Banyak sekolah milik kesultanan yang tidak menerima anak-anak Dayak, kecuali mereka telah beragama Islam. Termasuk sekolah milik pemerintah kolonial yang juga tidak kalah diskriminatif dalam menerima peserta didik.

Pada bidang pemerintahan, tidak banyak posisi yang bisa dijabat oleh orang Dayak kecuali kepala desa/kampung. Pada masa politik etis perhatian-perhatian untuk menaikkan taraf hidup masyarakat Dayak mulai dilakukan. Meskipun masih terbatas, masyarakat Dayak sudah ada yang mulai mengenyam pendidikan modern antara lain salah seorang pendiri Partai Persatuan Dayak - Johanes Chrisostomus Oevaang Oeray.

Oevang Oeray lahir di Kedamin, Kapuas Hulu pada 18 Agustus 1922 dari orang tua yang bermata pencaharian sebagai petani. Ia anak keempat dari empat bersaudara. Selain membantu orang tuanya bertani, ia menempuh pendidikan di Volkschool atau Sekolah Rakyat (SR). Setelah lulus ia memilih melanjutkan pendidikannya di Sekolah Seminari Katolik Nyarumkop, 
Singkawang selama enam tahun. Kemudian Oeray melanjutkan lagi ke tingkatan lebih tinggi yakni Sekolah Seminari Pastor. ${ }^{1}$

Sejak sekolah di Seminari kesadaran Oeray akan nasib bangsa Indonesia terutama Suku Dayak mulai tergugah. Ia mulai memikirkan kondisi sosial masyarakat Dayak yang harus ditingkatkan dan diperjuangkan secara politik. Pada tahun 1941, Oevaang Oeray menulis surat yang ditujukan kepada guru-guru Sekolah Katolik yang sedang mengadakan retreat (tur rohani) tahunan di Sanggau. Surat tersebut pada intinya berisi ajakan kepada guru-guru sekolah Katolik untuk memikirkan perbaikan nasib masyarakat Dayak yang terus dalam kondisi memperihatinkan.

Retreat dipimpin oleh AF. Korak, J.R Gielling Laut, dan M. Th Djaman. Efek dari surat Oeray itu melahirkan kebulatan tekad untuk membentuk organisasi yang memperjuangkan nasib suku Dayak di forum politik. Akan tetapi hal ini harus dibayar mahal dengan dikeluarkannya Oeray dari Seminari Pastor yang mengejutkan para pimpinannya. Oeray dianggap terlalu jauh membawa permasalahan politik ke dalam kegiatan kegerejaan yang seharusnya harus bebas dari muatan tersebut. ${ }^{2}$

Pembentukan organisasi itu baru terealiasi paska kemerdekaan RI, tepatnya pada 3 November 1945. Organisasi itu bernama Dayak in Action (DIA) yang dibentuk dalam rapat para guru dan pemuka Dayak di Putussibau. DIA menjadi suatu embrio bagi perjuangan dan kebangkitan Dayak yang masih berhubungan dengan berdirinya Partai Persatuan Dayak (PPD) kelak. Pada pertemuan tersebut disepakati juga Franciskus Conradus Palaunsuka, seorang guru sekolah Katolik, sebagai ketua pertamanya. ${ }^{3}$

Pada 22 Oktober 1945 wilayah Kalimantan Barat telah berhasil diduki oleh NICABelanda. Akan tetapi berkuasanya kembali Belanda nyatanya cukup menguntungkan dan memberi dampak positif bagi kepentingan politik masyarakat Dayak. Pada Januari 1946 dibentuk Dayak Affairs Office (DAO) atau Kantor Urusan Dayak, pertama kali diketuai oleh Oevaang Oeray. ${ }^{45}$ Kemudian di badan West Borneo Raad, Oktober 1946, orang Dayak juga

\footnotetext{
${ }^{1}$ Syafaruddin Usman dan Aju, J.C Oevaang Oeray: Memoar Politik. Penerbit Samudera Mas, Pontianak, 2012 HIIm: 133-134

${ }^{2}$ Taufiq Tanasaldy, Regime Change and Ethnic Politics in Indonesia: Dayak Politics of West Kalimantan, KITLV, Koninklijk Brill NV, Leiden, 2014: hlm. 90

${ }^{3}$ Usman dan Aju, op.cit. hlm. 75

${ }^{4}$ Tanasaldy, op.cit. hlm. 86

${ }^{5}$ Oevaang Oeray bersama J.A.M Linggie dan G.P. Djaoeng sempat dikirim oleh NICA untuk mengikuti pendidikan di MOSVIA (Sekolah Pengreh Praja) di Makassar. Akan tetapi Oeray tidak mengikuti pendidikan ini hingga selesai karena Sultan Hamid II memanggilnya untuk mengetuai DAO pada Januari 1946. Ibid.

Jurnal Swadesi, Volume I Nomor 1 Tahun 2020 
dilibatkan dengan tugas memberikan masukan dan pertimbangan untuk Asisten Residen. Kesempatan ini menjadikan untuk pertama kalinya suku Dayak terlibat dalam pemerintahan dan pengambilan keputusan daerah. ${ }^{6}$

Pada 1 Oktober 1946 di Putussibau, DIA berganti nama menjadi Partai Persatun Dayak (PPD) dengan Ketua Umumnya F.C Palaunsuka dan Ketua dijabat oleh Marinus Andjioe. Keputusan ini merupakan salah satu dampak dari Konferensi Malino 16-25 Juli 1946 di Sulawesi Selatan. Dalam konferensi tersebut Oevaang Oeray hadir sebagai wakil Kalimantan Barat. Hal ini menunjukkan kedekatan romantika historis politik Dayak dengan Belanda sejak masuknya gerakan misi/politik etis. Selain itu kolaborasinya bersama Sultan Hamid II menunjukkan peran politisi Dayak sangat besar dalam politik lokal di Kalimantan Barat kala itu. ${ }^{7}$ Melalui pembentukan PPD itulah golongan elite politik Dayak ingin membuktikan potensi kekuatan politik yang lebih nyata sebagai representasi masyarakat Dayak. ${ }^{8}$ Kedepannya, Oevaang Oeray dan Sultan Hamid II menjadi duo kekuatan politik golongan pro-Belanda di wilayah itu.

Sebagai suatu partai PPD memiliki empat tujuan (objectives), yakni: 1) untuk meningkatkan harga diri orang Dayak setelah mengalami penekanan baik oleh peraturanperaturan kolonial maupun kesultanan Melayu. 2) untuk menciptakan kesamaan hak dan menghapus diskriminasi serta nepotisme dalam perekrutan pegawai sipil. 3) untuk menghapus perlakukan-perlakukan khusus atau pajak yang hanya dikenakan pada masyarakat Dayak. 4) mencapai kebebasan politik.

Pada Desember 1946 hasil keputusan rapat PPD di Putussibau, menetapkan pemindahan kedudukan sekretariat ke Pontianak. Hal ini bertujuan untuk dapat lebih berpartisipasi pada pertumbuhan politik di Pontianak, selain itu dengan berkedudukan di ibukota provinsi juga akan menjadi nilai prestis tersendiri bagi partai. ${ }^{9}$ Dengan berpindahnya kedudukan PPD ke Pontianak maka dibentuklah organ baru yakni Dewan Pimpinan Pusat yang diketuai oleh Oevaang Oeray terhitung sejak 1 Januari 1947.

\footnotetext{
${ }^{6}$ lbid., hlm. 81

7 Dwi Putra Nugraha, Partai Politik Lokal di Indonesia: Analisis Kedudukan dan Fungsi Partai Politik Lokal 19552011, Tesis, Universitas Indonesia, Jakarta: 2012: hlm. 120

${ }^{8}$ Dalam hal ini sebenarnya tidak semua tokoh Dayak sepakat dengan arah politik PPD yang mendukung DIKB dan Pro-Belanda. Salah satunya Djeranding Abdurahman, eks-digulis yang mengecam DIKB dan mendorong agar segera berintegrasi dengan RI. Lihat Syafaruddin Usman dan Aju, Djerandeng Abdurahman: Perjuangan Digoelis Kalimantan Barat Persembahkan Kemerdekaan Rl, tanpa penerbit, Pontianak, 2012: hlm. 12

${ }^{9}$ Tanasaldy, op.cit., hlm. 92

Jurnal Swadesi, Volume I Nomor 1 Tahun 2020
} 
Pada 12 Mei 1947 sebagai strategi untuk menyudutkan RI dengan membentuk negaranegara federal, Belanda membentuk Daerah Istimewa Kalimantan Barat (DIKB) yang dipimpin oleh Sultan Hamid II. Dalam strukturnya, delapan petinggi PPD seperti Oeray dan Palaunsuka juga tergabung dalam Badan Pemerintah Harian (BPH) yang bertugas untuk membantu pemimpin DIKB. Hal ini cukup disayangkan bagi golongan pro-republik di Kalimantan Barat, namun ketergabungan unsur PPD dalam BPH-DIKB merupakan tekad untuk tetap dapat mengangkat derajat etnis dayak paska kemerdekaan agar sejajar dan ikut terlibat dalam pengambilan keputusan. ${ }^{10}$ DIKB tetap menolak bergabung dalam RI meskipun telah terjadi pengembalian kedaulatan paska KMB 27 Desember 1949. Padahal kondisi politik di Kalimantan Barat sudah semakin banyak yang mendesak agar DIKB bergabung dengan RI, salah satunya oleh Komite Nasional Kalimantan Barat (KNKB) pimpinan Tan Husni Abdullah dan S.H. Marpaung. ${ }^{11}$

Arah politik PPD mulai berubah lewat dua peristiwa penting pada 1950. Pertama, PPD menganggap DIKB sudah tidak berfungsi setelah ditangkapnya Sultan Hamid pada 5 April 1950 karena terlibat kup APRA pada 5 Januari. Pada bulan itu juga PD mulai mendukung pembentukan negara unitaris (kesatuan), namun dengan pemberian status otonomi dan pembentukan Kalimantan Barat yang otonom. Kemudian pada 7 Mei 1950 Dewan Eksekutif memutuskan untuk membubarkan DIKB dan bergabung dengan RI. ${ }^{12}$ Kedua, pada 17 Agustus 1950, Presiden Sukarno mengumumkan pembubaran RIS, sehingga Indonesia secara resmi kembali ke bentuk negara kesatuan. Maka usaha-usaha Belanda untuk memecah Indonesia melalui pembentukan negara boneka telah gagal.

\section{METODE}

Penelitian ini menggunakan metode penelitian sejarah yang memiliki urutan metodologi sebagai berikut: menemukan sumber sejarah atau heuristik, kritik atau verifikasi, interpretasi, eksplanasi (penjelasan) dan historiografi (Wasino, 2006:12). Peneliti melakukan pengumpulan sumber seperti literature, surat kabar sezaman dan lain sebagainya. Kritik sumber dilakukan

\footnotetext{
${ }^{10}$ Hiski Darmayana, Oevaang Oeray Pejuang Dayak Soekarnois, Berdikari Online 2 Januari 2014, diunduh dari http://www.berdikarionline.com/oevaang-oeray-pejuang-dayak-soekarnois/pada 24 Agustus 2018

${ }^{11}$ KNKB merupakan faksi politik gabungan dari berbagai organisasi/organisasi politik yang pro terhadap pemerintahan RI dan negara kesatuan (unitaris). Lihat Nugraha, op.cit. hlm. 130

${ }^{12}$ Tanasaldy, op.cit. hlm. 95-96

Jurnal Swadesi, Volume I Nomor 1 Tahun 2020
} 
sebagai upaya untuk melihat otensitas, kredibilitas dan kelayakan sumber untuk digunakan dalam penulisan artikel ini.

\section{HASIL DAN PEMBAHASAN}

\section{Perjuangan PPD Menghadapi Pemilu 1955}

Dibubarkannya DIKB dan RIS pada tahun 1950 awalnya menjadi kekhawatiran bagi elite politik PPD akan perjuangan mereka ke depan. Cap sebagai faksi politik yang pro kesultanan feudal dan pro Belanda tidak begitu saja mudah sirna meski PPD pada akhirnya berbalik mendukung NKRI. Oevaang Oeraay sendiri diangkat menjadi Bupati Kapuas Hulu pada tahun tersebut, meskipun tidak sedikit anggapan sebenarnya ini hanya usaha untuk menjauhkannya dari perpolitikan di Pontianak.

Sebagai usaha untuk "menghidupkan" kembali PPD agar dapat memainkan peranan dalam perpolitikan lokal di Kalimantan Barat, pengurus mengadakan beberapa kongres partai. Kongres pertama dilaksanakan di Sanggau pada 13 Juli 1950 dan berhasil mengesahkan AD/ART partai yang baru. Sedangkan kongres kedua dilaksanakan di Pahauman, Kabupaten Landak pada 29-30 Desember 1951. ${ }^{13}$

PPD menggunakan cara baru agar dapat kembali bermain di politik lokal, hal ini sebenarnya ajang untuk membuktikan betapa besarnya potensi suara masyarakat Dayak. Komitmen PPD akan demokrasi membuat partai ini harus berjuang keras melalui pemilu. Pada 4 April 1953 UU No. 7 Tahun 1953 tentang Pemilihan Anggota Konstituante dan DPR mulai berlaku dan cukup lengkap mengatur tentang hak pilih hingga ketentuan pidana apabila ada pelanggaran pemilu. ${ }^{14}$

Untuk memenangi pemilu PPD melaksanakan beberapa strategi yang cukup bagus untuk mendulang suara. Selain melaksanakan program-program konsolidasi dan pengkaderan, PPD menyasar suara pemilih dari kalangan akar rumput masyarakat Dayak yang amat luas di seluruh Kalimantan Barat. Mulai dari rakyat pedesaan, pegawai sipil etnis dayak, hingga dari kalangan gereja Katolik. PPD juga membentuk cabangnya di luar Kalimantan Barat, salah satunya

\footnotetext{
${ }^{13}$ Anton Habibi, Partai Persatuan Dayak: Parpol Pertama Suku Bangsa Dayak Kalimantan, Kamis 20 Maret 2014, diunduh dari http://suarapakat.blogspot.com/2014/03/partai-persatuan-dayak-pd-partai.html 25 Agustus 2018

${ }^{14}$ UU No. 7 Tahun 1953 tentang Pemilihan Anggota Konstituante dan Anggota Dewan Perwakilan Rakyat, diunduh dari www. hukumonline.com pada 25 Agustus 2018

Jurnal Swadesi, Volume I Nomor 1 Tahun 2020
} 
Banjarmasin. Cabang PPD di Banjarmasin dipimpin oleh Timmerman Brahim, dengan isu yang diperjuangkan yakni mendorong pembentukan provinsi Kalimantan Tengah. ${ }^{15}$

PPD juga hubungan baik dengan beberapa partai nasional di Kalimantan Barat, terutama PNI. Soal pendanaan, PPD menerima sumbangan sebesar tiga 3\% dari gaji pegawai sipil etnis Dayak selain sumbangan wajib anggota. Dengan membawa identitas politik sebagai "partainya orang Dayak", kader-kader PPD cukup aktif melakukan turne ke berbagai daerah demi menggalang massa pemilih. ${ }^{16}$ PPD juga memiliki sumber pendanaan dari perusahaan perdagangan N.V Tjemara yang didirikan berkat bantuan Lim Bak Meng, pengusaha Tionghoa anggota PPD. Akan tetapi perusahaan ini kurang berhasil dalam melakukan pengumpulan dana yang diperlukan partai. Pada 16-18 Desember 1954 PPD kembali mengadakan kongres yang ketiga di Pontianak. ${ }^{17}$

Pemilu 1955 diikuti oleh 118 peserta yang terdiri dari partai politik, gabungan organisasi politik, hingga calon perorangan. Menurut pendataan di tahun 1954, pemilih berjumlah 43.104.464 orang. Pemilu 1995 menetapkan setiap 300.000 jiwa untuk satu kursi DPR, dan Konstituante setiap satu kursinya mewakili 150.000 jiwa. Dengan dimikian sebanyak 260 kursi DPR tersedia berbanding Konstituante sebanyak 520 kursi. Pada 29 September 1955 dilakukan pemilihan suara untuk memilih anggota DPR, sebanyak 37.785.299 atau sekitar 87\% pemilih menggunakan suaranya secara sah. Sedangkan pemilu untuk memilih anggota Konstituante tanggal 15 Desember 1955, terjadi sedikit kenaikan yakni sejumlah 37.837 .105 pemilih. ${ }^{18}$

Hasil menggembirakan diraih PPD, secara umum perjuangan partai tersebut dalam mendulang suara dikatakan berhasil. Dalam Pemilu DPR 29 September 1955, PPD meraih 146.054 suara dan berada di urutan kedua di Kalimantan Barat setelah Masyumi (155.173 suara). Sedangkan Pemilu Konstituante PPD keluar sebagai juara di provinsi itu dengan raihan 157.490 suara (Masyumi 152.715 suara). ${ }^{19}$

\footnotetext{
${ }^{15}$ Kalimantan Tengah saat itu masih bergabung dengan Kalimantan Selatan beribukota d Banjarmasin. Habibi,op.cit.

${ }^{16}$ Seperti dikisahkan oleh Iman Kalis, Ketua PPD di Sintang tahun 1954, ia melakukan turne bersama di wilayah sepanjang Sungai Sepauk. Iman Kalis dan rombongan berhasil meyakinkan masyarakat Dayak yang sebenarnya sudah menjadi anggota Parpol lain untuk pindah ke haluan ke PPD. Christophorus Franciscus Iman Kalis, Sebuah Otobiografi, Penerbit Kanisius, Yogyakarta, 2014, HIm. 438-439

17 Jamie S. Davidson, Primitive Politics: The Rise and Fall of the Dayak Unity Party in West Kalimantan Indonesia, Asia Research Institute of National University of Singapore, Singapore, 2003: hlm 1

${ }^{18}$ Komisi Pemilihan Umum Republik Indonesia, Modul I Pemilih Untuk Pemula, Jakarta, tanpa tahun: hlm 35-36

19 Tanasaldy, op.cit. HIm. 100
}

Jurnal Swadesi, Volume I Nomor 1 Tahun 2020 


\section{Dampak Kemenangan PPD Paska Pemilu 1955}

Perolehan suara yang diraih PPD belum lama itu menjadi sensasi besar, di DPR Daerah Swapraja Tingkat (Daswati) I Kalimantan Barat PPD meraih 12 dari 30 kursi yang diperebutkan. ${ }^{20}$ Sedangkan di DPR Daswati II, PPD leading di Kabupaten Pontianak 13 dari 30 kursi, Sanggau 12 dari 19 kursi, Sintang 9 dari 16 kursi, dan Kapuas Hulu 7 dari 15 kursi. PPD hanya gagal mendapatkan suara mayoritas DPR Daswati II di Sambas mendapatkan 5 dari 28 kursi, Ketapang mendapatkan 4 dari 15 kursi, dan Kotapraja Pontianak 2 dari 15 kursi. $^{21}$ Kekalahan PPD di tiga wilayah tersebut sebenarnya bukan suatu hal yang mengejutkan. Pasalnya wilayah pesisir barat Kalimantan memang didominasi oleh etnis Melayu yang orientasi politiknya ke partai yang bersifat nasional seperti Masyumi, PNI, atau PKI.

Selain kemenangan meraih kursi di DPR Daswati baik tingkat I dan II, PPD juga berhasil mendapatkan 1 kursi di DPR-RI dan 3 kursi pada dewan Konstituante. Pemilu 1955 menempatkan PPD di urutan ke-21 menyumbangkan 0.39\% suara sah nasional untuk DPR, dan $0.45 \%$ untuk Konstituante. Wakil PPD yang duduk di kursi DPR-RI adalah F.C Palaunsuka. Sementara wakil untuk dewan Konstituante PPD mengirimkan J.C Oevaang Oeray, Agustinus Djelani, dan Wilibrordus Hittam.

Hasil kurang memuaskan didapatkan PPD di wilayah lain di luar Kalimantan Barat. Cabang PPD di Banjarmasin yang merupakan Dewan Pimpinan Wilayah untuk Kalimantan Selatan tidak berhasil membawa partai ini setidaknya di papan tengah raihan suara di wilayah itu. Sebanyak $82 \%$ suara di diperoleh oleh dua partai islam, yakni Nahdlatul Ulama sebesar 49\% dan Masyumi 33\% persen, sedangkan PNI dengan 6\% suara. Bahkan di daerah yang di dominasi oleh masyarakat Dayak, seperti Barito, Kapuas, dan Kotawaringin, raihan suara PPD juga tidak bisa berbicara banyak. ${ }^{22}$ Kegagalan di wilayah ini dikarenakan masyarakat Dayak memberikan dukungannya menyebar ke berbagai partai. Banyak politikus Dayak enggan

\footnotetext{
${ }^{20}$ Berdasarkan UU No. 14 Tahun 1956 juncto Permendagri No. 12 Tahun 1956 disebutkan bahwa DPRD Daswati I Kalbar berubah berstatus menjadi DPRD Peralihan dengan komposisi 30 orang berdasarkan jumlah suara pada Pemilu 1955. DPRD Peralihan selanjutnya akan dibubarkan apabila telah terpilih anggota DPRD baru hasil pemilu daerah yang kelak akan dilaksanakan pada 1958. Disebut peralihan karena Kalimantan Barat sedang disiapkan akan menjadi provinsi tersendiri, dan DPRD peralihan penting keberadaanya agar tidak terjadi pemerintahan tunggal (eenhofdig bestuur) yang dapat mengancam demokrasi pada tingkat lokal. Lihat Nugraha, op.cit. HIm 140

${ }^{21}$ Kalis, op.cit., HIm. 289-290

${ }^{22}$ Habibi, op.cit.
}

Jurnal Swadesi, Volume I Nomor 1 Tahun 2020 
menjadikan "Dayak" sebagai suatu penanda identitas politik dan menurut mereka hal ini tidak menarik. $^{23}$

Kembali ke Kalimantan Barat, kemenangan PPD dalam pemilu 1955 di tingkat lokal telah mengembalikan elite politik Dayak menguasai hegemoni perpolitikan. Kemenangan PPD membawa pengaruh bagi masyarakat Dayak di seluruh Kalimantan Barat, harkat dan martabat mereka terangkat dengan kemenangan "partainya orang Dayak" tersebut. Para politikus Dayak non PPD maupun tokoh-tokoh Dayak non partai yang sebelumnya cukup menjaga jarak dengan partai itu karena takut maupun karena kurangnya rasa percaya diri mulai mendekati PPD. Bahkan beberapa kader partai lain berpindah ke PPD, salah satunya Petrus Anjiem, pengurus PNI di Landak. ${ }^{24}$

Sebagai bukti timbulnya kepercayaan diri masyarakat Dayak, orang-orang Senganan, ${ }^{25}$ juga mendekati PPD. Mereka ingin membuktikan kembali akar budayanya yang berasal dari suku Dayak. PPD akhirnya menerima orang-orang Senganan dalam struktur kepartaian, M. Idris misalnya dipercayai memimpin PPD di Sambas dan Sadjali Usman di Kotapraja Pontianak. ${ }^{26}$ Orang-orang Tionghoa juga tidak sedikit bergabung dengan PPD. Dengan demikian citra PPD yang semula lekat sebagai partai untuk golongan tertentu mulai terhapus dan bergeser menjadi partai yang lebih universal.

Pengaruh kemenangan PPD di Kalimantan Barat menjadikan partai ini memiliki posisi daya tawar yang tinggi untuk mengisi jabatan-jabatan pemerintahan yang diperlukan. Pada 28 Januari 1957 DPRD Peralihan Daswati I Kalimantan Barat berdasarkan Permendagri No. 17 Tahun 1956 membentuk Dewan Pemerintahan Daerah (DPD) Peralihan. Sebanyak dua dari lima anggota DPD Peralihan Daswati I Kalimantan Barat diisi oleh kader PPD yakni Isidorus Kaping dan H.S Massoeka Djanting. ${ }^{27}$ Sementara ditingkat Daswati II, PPD juga berhasil menempati wakilnya antara lain di; Kabupaten Pontianak, Sintang, dan Kapuas Hulu masing-

\footnotetext{
${ }^{23}$ Gerry van Klinken, Dayak Ethnogenesis \& Conservative Politics in Indonesia Outer Islands. KITLV,Leiden, 2004: 41

${ }^{24}$ Tanasaldy, op.cit. HIm. 101

${ }^{25}$ Senganan adalah golongan orang Dayak yang telah meninggalkan budaya aslinya dan menjadi suku tertentu, terutama Melayu dan telah memeluk Islam.

${ }^{26}$ Tanasaldy, loc. cit

${ }^{27}$ Nugraha, op. cit. HIm. 140
}

Jurnal Swadesi, Volume I Nomor 1 Tahun 2020 
masing dua orang, Sambas dan Ketapang masing-masing satu kursi, serta Sanggau mengamankan tiga kursi. ${ }^{28}$

Pada 22 Mei 1958 dilaksanakan Pemilu Lokal untuk memilih anggota DPRD Provinsi maupun Kabupaten/Kota. Dalam pemilu ini terbukti mesin politik PPD tetap berjalan dengan baik. PPD berhasil mengalahkan partai berskala nasional seperti Masyumi dengan mendapatkan dua belas kursi dari tigapuluh yang tersedia. Masyumi sendiri mendapatkan hanya sembilan kursi. ${ }^{29}$ Di DPRD Kabupaten/Kota PPD juga meraih kemenangan di beberapa daerah seperti; Kabupaten Pontianak 13 dari 30 kursi, Sanggau 12 dari 19 kursi, Sintang 9 dari 16 kursi, Kapuas Hulu 7 dari 15 kursi, Sambas 5 dari 28 kursi, Ketapang 4 dari 15 kursi, dan Kotapraja Pontianak 2 dari 15 kursi. $^{30}$

Kemenangan PPD pada Pemilu Lokal 1958 yang mengesankan disusul terpilihnya kaderkader PPD sebagai kepala daerah/bupati. Lewat lobi-lobi politik, calon-calon yang diajukan PPD terpilih melalui sidang DPRD Kabupaten antara lain; J.R Gielling Laut di Kapuas Hulu, G.P. Djaoeng di Sintang, M. Th Djaman di Sanggau, dan Agustinus Djelani di Kabupaten Pontianak. ${ }^{31}$ Kedigdayaan PPD semakin sempurna karena selain mendominasi pada kekuasaan eksekutif, juga dalam kekuasaan legislatif. Kader-kadernya juga terpilih menjadi Ketua DPRD di Sanggau, Sintang, dan Kapuas Hulu, serta Wakil Ketua DPRD di Kabupaten Pontianak dan DPRD Provinsi Kalimantan Barat. ${ }^{32}$

Masih pada bulan Mei 1958, PPD mengadakan Kongres Akbar di Sintang dengan menghasilkan beberapa keputusan, diantaranya perubahan AD/ART dan susunan kepengurusan yang kini kembali dipegang oleh F.C Palaunsuka. ${ }^{33}$ Kongres ini juga digunakan untuk mempersiapkan ajang pemilihan Gubernur Kalimantan Barat yang sedianya dilaksanakan tahun 1959 lewat mekanisme sidang DPRD.

\footnotetext{
${ }^{28}$ Tentang DPD Peralihan, ialah badan yang melangsungkan dan bertanggungjawab terhadap tugas-tugas eksekutif/pemerintahan terdiri dari departemen harian dan bertanggungjawab kepada DPRD. Tanasaldy, loc.cit.

${ }^{29}$ Davidson, op.cit. HIm. 16

${ }^{30}$ Nugraha, op.cit. HIm 141

${ }^{31}$ Usman, J.C Oevaang Oeraay: Harkat dan Martabat Kalimantan Barat, Penerbit Engga Media, Pontianak, hlm. 58

32 Tanasaldy, op. cit., HIm. 104

${ }^{33}$ Habibi, op.cit.
}

Jurnal Swadesi, Volume I Nomor 1 Tahun 2020 
Agar dapat diajukan sebagai calon Kepala Daerah untuk selanjutnya ditetapkan oleh Presiden RI, maka PPD berkoalisi dengan PNI. ${ }^{34}$ Meskipun tidak berkoalisi, PKI juga memberikan dukungannya kepada Oevaang Oeray. ${ }^{35}$ Pada 17 Maret 1959 dikeluarkan Keputusan Presiden RI No. 59/M tentang penetapan J.C Oevaang Oeray, (menyisihkan Muzani A. Rani-Masyumi), sebagai Kepala Daerah Daswati I Kalimantan Barat. ${ }^{36}$

Kemudian berdasarkan Keputusan Presiden No. 465/M Tahun 1959 tanggal 24 November 1959 Oevang Oeray ditetapkan sebagai gubernur terpilih oleh Presiden Sukarno dengan menyisihkan R.P.M Lumban Tobing dari PNI. Keputusan itu juga sebagai instruksi untuk menyatukan jabatan Gubernur dan Kepala Daerah yang sebelumnya terpisah. Maka terhitung sejak 1 Januari 1960 J.C Oevaang Oeray mulai menjabat sebagai Gubernur Kepala Daerah Kalimantan Barat. ${ }^{37}$ Dengan ini maka sejarah akan mencatat dalam Pemilu 1955 (dan 1958) PPD lah satu-satunya partai politik kedaerahan yang sanggup menguasai perpolitikan di wilayahnya sendiri

\section{KESIMPULAN}

Partai Persatuan Dayak yang didirikan oleh para kaum terdidik Dayak di Kalimantan Barat bermetamorfosa dengan cepat hanya dalam tempo sepuluh tahun. Sebagai partai yang digunakan untuk memajukan taraf hidup dan harkat martabat masyarakat Dayak, PPD seakan menjadi simbol mulai bangkitnya masyarakat Dayak dari ketepurukan. Pandangan perlunya memikirkan nasib masyarakat Dayak ke depan oleh J. C Oevaang Oeraay dan dieksekusi dalam sebuah organisasi politik, seperti yang didirikan oleh F.C Palaunsuka dan yang lainnya menjadi pelecut perjuangan masyarakat Dayak agar dapat setaraf dengan suku lainnya.

Maka dari pembahasan di atas dapat ditarik beberapa kesimpulan. Pertama, kesadaran politik memperjuangkan Dayak baru tumbuh paska kemerdekaan RI. Hal ini dikarenakan pada masa kolonial masyarakat Dayak kurang mendapatkan akses pendidikan yang baik. Termasuk mengalami diskriminasi di bidang sosial, orang-orang Dayak tidak pernah diikutsertakan dalam pengambilan keputusan. Oleh sebab itulah DIA didirikan pada 3 November 1945

\footnotetext{
${ }^{34}$ PPD awalnya mengajak Masyumi untuk berkoalisi, namun ditolak karena hendak mengajukan calon sendiri. PPD kemudian mengajak PNI berkoalisi, dengan kesepakatan bila menang Abdulsyukur (PNI) duduk sebagai Ketua DPRD Provinsi Kalimantan Barat. Lihat Kalis, op.cit. HIm. 291

${ }^{35} \mathrm{PKI}$ sebenarnya anti terhadap politik kesukuan, toh dukungan ini tetap dilakukan demi menjaga jarak dengan Masyumi yang merupakan musuh utama PKI. Lihat Usman, op.cit., hlm. 25 dan 27

36 Nugraha, op.cit., HIm. 141

${ }^{37}$ Davidson, op.cit., HIm. 16 Lihat catatan kaki no. 70

Jurnal Swadesi, Volume I Nomor 1 Tahun 2020 
sebagai embrio kebangkitan politik Dayak. Perlahan masyarakat Dayak mulai ikut serta dalam pemerintahan di Dayak Affairs Office 1945-1947 masa NICA maupun dalam BPH-DIKB pada 1947-1950. Pada 30 November 1946 DIA berubah menjadi PPD untuk semakin memajukan masyarakat Dayak.

Kedua, pada periode 1950-1955 PPD berjuang keras untuk memenangi Pemilu 1955. PPD melakukan berbagai strategi mulai dari kongres partai, konsolidasi, kaderisasi, pengumpulan dana untuk operasional partai, hingga melakukan kampanye hingga ke pelosokpelosok desa. Semua itu dilakukan untuk meyakinkan massa, terutama masyarakat Dayak, untuk mendukung PPD dalam pemilu. Hasilnya, PPD berada di urutan dua Pemilu DPR dengan 9 kursi DPRD dan urutan satu pada Pemilu Konstituante.

Ketiga, atas kemenangan tersebut PPD berhasil mengirimkan satu wakilnya di DPR RI atas nama F.C Palaunsuka dan tiga orang di Konstituante atas nama J.C Oevaang Oeray, Wilibrordus Hittam, dan Agustinus Djelani. PPD juga berhasil menjadikan kadernya sebagai Bupati di Kapuas Hulu, Sintang, Sanggau dan Kabupaten Pontianak. PPD juga menduduki posisi strategis sebagai Ketua DPRD Daswati II diantaranya di Sanggau, Sintang, dan Kapuas Hulu. Di DPRD Daswati I, anggota PPD menduduki posisi wakil ketua. Selain itu anggota PPD juga menduduki beberapa departemen di DPD baik tingkat provinsi maupun kabupaten kota. Setelah berhasil menguasai kekuasaan eksekutif dan legislatif, PPD akhirnya berhasil mengantarkan J.C Oevaang Oeray sebagai Gubernur/Kepala Daerah Provinsi Kalimantan Barat yang pertama.

\section{DAFTAR PUSTAKA}

Habibi.A., Partai Persatuan Dayak: Parpol Pertama Suku Bangsa Dayak Kalimantan, Kamis 20 Maret 2014, diunduh dari http://suarapakat.blogspot.com/2014/03/partai-persatuandayak-pd-partai.html 25 Agustus 2018

Kalis.Christophorus.F.I, 2014. Sebuah Otobiografi, Penerbit Kanisius, Yogyakarta

Nugraha.Dwi Putra., 2012. Partai Politik Lokal di Indonesia: Analisis Kedudukan dan Fungsi Partai Politik Lokal 1955-2011, Tesis, Universitas Indonesia, Jakarta

Gerry, 2004. Dayak Ethnogenesis \& Conservative Politics in Indonesia Outer Islands. KITLV, Leiden 
Hiski Darmayana, Oevaang Oeray Pejuang Dayak Soekarnois, Berdikari Online 2 Januari 2014, diunduh dari http://www.berdikarionline.com/oevaang-oeray-pejuang-dayaksoekarnois/ pada 24 Agustus 2018

Jamie S. Davidson, 2003. Primitive Politics: The Rise and Fall of the Dayak Unity Party in West Kalimantan Indonesia, Asia Research Institute of National University of Singapore, Singapore

Komisi Pemilihan Umum Republik Indonesia, tanpa tahun, Modul I Pemilih Untuk Pemula, tanpa penerbit, Jakarta

Syafaruddin Usman, 2018. J.C Oevaang Oeraay: Harkat dan Martabat Kalimantan Barat, Penerbit Enggang Media, Pontianak

Syafaruddin Usman dan Aju, 2012. J.C Oevaang Oeray: Memoar Politik. Penerbit Samudera Mas, Pontianak.

2012. Djerandeng Abdurahman: Perjuangan Digoelis Kalimantan Barat Persembahkan Kemerdekaan RI, tanpa penerbit, Pontianak, 2012

Taufiq Tanasaldy, 2014. Regime Change and Ethnic Politics in Indonesia: Dayak Politics of West Kalimantan, KITLV, Koninklijk Brill NV, Leiden

UU No. 7 Tahun 1953 tentang Pemilihan Anggota Konstituante dan Anggota Dewan Perwakilan Rakyat, diunduh dari www.hukumonline.com pada 25 Agustus 2018 